\title{
cmaJOPEN
}

\section{Association of diabetes with frequency and cost of hospital admissions: a retrospective cohort study}

\author{
Jin Choi MD MSc, Gillian Booth MD MSc, Hae Young Jung MSc, Lauren Lapointe-Shaw MD PhD,
} Terence Tang MD, Janice L. Kwan MD MPH, Shail Rawal MD MPH, Adina Weinerman MD MHSc, Amol Verma MD MPhil, Fahad Razak MD MSc

\section{Abstract}

Background: Acute inpatient hospital admissions account for more than half of all health care costs related to diabetes. We sought to identify the most common and costly conditions leading to hospital admission among patients with diabetes compared with patients without diabetes.

Methods: We used data from the General Internal Medicine Inpatient Initiative (GEMINI) study, a retrospective cohort study, of all patients admitted to a general internal medicine service at 7 Toronto hospitals between 2010 and 2015. The Canadian Institute for Health Information ( $\mathrm{ClHI}$ ) Most Responsible Diagnosis code was used to identify the 10 most frequent reasons for admission in patients with diabetes. Cost of hospital admission was estimated using the $\mathrm{CIHI}$ Resource Intensity Weight. Comparisons were made between patients with or without diabetes using the Pearson $\chi^{2}$ test for frequency and distribution-free confidence intervals (Cls) for median cost.

Results: Among the 150499 hospital admissions in our study, 41934 (27.8\%) involved patients with diabetes. Compared with patients without diabetes, hospital admissions because of soft tissue and bone infections were most frequent $(2.5 \% \mathrm{v}$. $1.9 \%$; prevalence ratio $[\mathrm{PR}] 1.28,95 \% \mathrm{Cl} 1.19-1.37$ ) and costly (Can\$8794 v. Can\$5845; cost ratio [CR] 1.50, 95\% Cl 1.37-1.65) among patients with diabetes. This was followed by urinary tract infections (PR 1.16, 95\% Cl 1.11-1.22; CR 1.23, 95\% Cl 1.17-1.29), stroke (PR 1.13, 95\% Cl 1.07-1.19; CR 1.19, 95\% Cl 1.14-1.25) and electrolyte disorders (PR 1.11, 95\% Cl 1.03-1.20; CR 1.20, 95\% Cl 1.08-1.34).

Interpretation: Soft tissue and bone infections, urinary tract infections, stroke and electrolyte disorders are associated with a greater frequency and cost of hospital admissions in patients with diabetes than in those without diabetes. Preventive strategies focused on reducing hospital admissions secondary to these disorders may be beneficial in patients with diabetes.

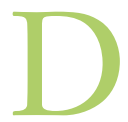
iabetes inflicts a heavy burden on health care systems globally. ${ }^{1}$ In Canada and the United States, nearly 1 in 10 people are diagnosed with diabetes, ${ }^{2,3}$ and this figure has been projected to increase to 1 in 5 people by $2050 .^{4}$ In 2008, diabetes cost Canada $\$ 2.18$ billion in the form of hospital admissions, physician care and medications. ${ }^{5}$ By 2022, new cases of diabetes have been estimated to cost an additional $\$ 15.36$ billion. ${ }^{6}$ In the US, one-quarter of all health care expenditures in 2017 were incurred by people with diabetes. ${ }^{3}$

Acute inpatient hospital admissions are the primary driver of health care costs related to diabetes in Canada and the US. In many jurisdictions, including Ontario, more than $50 \%$ of attributable costs in incident diabetes are ascribed to acute inpatient hospital admissions. ${ }^{3,7}$ Research has shown diabetes to portend a higher likelihood of heart failure, ${ }^{8}$ stroke $^{9}$ and renal failure ${ }^{10}$ However, there is a paucity of data describing the specific medical conditions that drive the increased fre- quency and cost of hospital admission among people with diabetes. Such population-level data could specifically guide public policy in strengthening support for greater outpatient services among people with diabetes.

The objectives of this study were to identify the most common and costly conditions leading to hospital admission among patients with diabetes compared with patients without diabetes.

Competing interests: Amol Verma and Fahad Razak report that they are part-time employees of Health Quality Ontario. No other competing interests were declared.

This article has been peer reviewed.

Correspondence to: Fahad Razak, Fahad.Razak@unityhealth.to CMAJ Open 2021. DOI:10.9778/cmajo.20190213 


\section{Methods}

\section{Study design and setting}

This is a retrospective cohort study using data collected by the General Internal Medicine Inpatient Initiative (GEMINI) study. A full description of the design and methods of the study has been presented previously. ${ }^{11}$ The GEMINI study involves 7 large hospital sites affiliated with the University of Toronto: St. Michael's Hospital, Toronto General Hospital, Toronto Western Hospital, Mount Sinai Hospital, Sunnybrook Health Sciences Centre, Credit Valley Hospital and Mississauga Hospital. The latter 2 hospitals are large community teaching hospitals serving the neighbouring city of Mississauga. The remaining GEMINI hospitals are academic health centres in Toronto (Appendix 1, available at www.cmajopen. ca/content/9/2/E406/suppl/DC1). All GEMINI hospitals are publicly funded, independently operated and provide tertiary or quaternary care.

\section{Study population}

We included all patients admitted to or discharged from the general internal medicine service at each hospital between Apr. 1, 2010, and Mar. 31, 2015. This included patients who required an intensive care unit (ICU) admission at any point during their hospital admission and those who were transferred to surgical services (e.g., for an amputation). There were no exclusion criteria.

General internal medicine admissions accounted for a substantial proportion of hospital admissions, including $39 \%$ of all emergency admissions. ${ }^{11}$ The most responsible care providers on the general internal medicine wards were predominantly internists. A separate inpatient cardiology ward was ubiquitous among all hospitals, but access to respirology, nephrology, hematology, gastroenterology, oncology and stroke wards varied. There were no separate endocrinology inpatient wards at any centres.

\section{Data sources and collection}

We collected patient-level characteristics for each admission, including demographic characteristics, diagnoses, interventions and discharge destination as reported by participating hospitals to the Canadian Institute for Health Information (CIHI) Discharge Abstract Database (DAD). Each individual-level record included age, sex, place of residence at time of admission and discharge, most responsible discharge diagnosis, diagnostic and therapeutic procedures, laboratory and radiology test results, blood transfusions, medications and intensive care unit admissions (Appendix 2, available at www.cmajopen.ca/ content/9/2/E406/suppl/DC1). Unique identifiers were used to link all data, and analyses on a subset of data showed $98 \%-$ $100 \%$ accuracy compared with chart review. ${ }^{12}$ Patients with diabetes were identified using CIHI Diagnosis Code (Group 10, Field 02) which conveys International Statistical Classification of Diseases and Related Health Problems, 10th Revision (ICD-10) codes as recorded in hospital administrative databases.

For each admission, we identified the primary discharge diagnosis using ICD-10 codes. Diseases were then classified into clinically relevant categories using Clinical Classifications Software, which organizes individual diagnoses into 285 mutually exclusive categories. ${ }^{11}$

To estimate the cost of each hospital admission comparably across sites and years, we used the CIHI Resource Intensity Weight (RIW) for each admission ${ }^{13}$ and multiplied this by the annual cost per weighted case for acute inpatient cases that was reported for each hospital using the Ontario Cost Distribution Methodology. ${ }^{14}$ The RIW is determined by CIHI using information collected in the DAD, which captures administrative, clinical and demographic information on hospital discharges from all acute inpatient separations (i.e., transfer, death, discharge or the patient leaving against advice) in Canada, with the exception of Quebec. Based on individual factors affecting medical complexity, including most responsible discharge diagnosis, age and comorbidities, every inpatient case is assigned an RIW by CIHI. This approach allows for the estimation of a nationally comparable cost for each hospital stay, including costs related to administration, staff, supplies, technology and equipment, but does not include fee-for-service physician billing costs. ${ }^{15}$ Data from CIHI have been validated previously ${ }^{16,17}$ and have reliably formed the basis for a substantial body of clinical and health services research. ${ }^{18,19}$

All costs were reported in Canadian dollars.

\section{Statistical analysis}

The study population was described using means and standard deviations (SDs) or medians and interquartile ranges (IQRs), as appropriate for continuous or interval variables, and frequencies for categorical variables. We compared patients with or without diabetes using a Pearson $\chi^{2}$ test for frequency and distribution-free confidence intervals (CIs) for median cost. ${ }^{20}$ For the top 10 most frequent reasons for admission among patients with diabetes, we compared frequency and cost of admission using prevalence ratios (PRs) and cost ratios (CRs). We computed PRs and CRs as the ratio of frequency or cost in patients with diabetes to the frequency or cost in patients without diabetes. ${ }^{21}$ Given large sample sizes, we determined differences to be meaningful if they were both statistically significant $(p<0.05)$ and relative differences were greater than $10 \%$.

We conducted sensitivity analyses using only the first hospital admission for all included patients and stratifying results by sex. We accounted for inflation by standardizing fiscal year cost of hospital stay to April 2015 using Canadian Agency for Drugs and Technologies in Health guidance and used the general consumer price index as a deflator. ${ }^{22}$ All analyses were conducted using R statistical software, version 3.3.2 (R Foundation for Statistical Computing).

\section{Ethics approval}

Research ethics board approval was obtained from all participating hospitals (Clinical Trials Ontario Study ID 1394). An exception from informed consent was obtained because this was a large retrospective study with minimal risk of reidentification for any individual patient. 


\section{Results}

There were 150499 admissions to general internal medicine wards across all hospital sites during the study period (Table 1). There were 97316 unique patients. Overall, 41934 (27.8\%) of all hospital admissions occurred in patients with diabetes, and most hospital admissions (94.1\%) were among patients with type 2 diabetes. Among all patients admitted to hospital, the median age was 73 years, $50.2 \%$ were female and the median number of comorbidities, including diabetes, was 6 .

\section{Frequency of admissions}

The most frequent reasons for admission to general internal medicine (Table 2, Table 3) among patients with diabetes were heart failure $(7.7 \%)$, urinary tract infection $(5.1 \%)$, stroke $(4.8 \%)$, pneumonia $(4.6 \%)$, chronic obstructive pulmonary disease $(4.4 \%)$, delirium $(3.2 \%)$, acute renal failure (2.9\%), sepsis $(2.8 \%)$, soft tissue and bone infections $(2.5 \%)$ and electrolyte disorders (2.4\%). Based on the Clinical Classifications Software group of electrolyte disorders, the most common were hyponatremia $(57.2 \%)$, dehydration (14.1\%), hypernatremia (10.2\%), hyperkalemia $(6.0 \%)$ and hypokalemia $(4.0 \%)$.

The PRs for these conditions (Figure 1, Table 3) showed that acute renal failure (PR 2.02, 95\% CI 1.87-2.17), heart failure (PR 1.88, 95\% CI 1.80-1.96), soft tissue and bone infections (PR 1.28, 95\% CI 1.19-1.37), sepsis (PR 1.22, 95\% CI 1.14-1.31), urinary tract infections (PR 1.16, 95\% CI 1.11-1.22), delirium (PR 1.15, 95\% CI 1.08-1.23), stroke (PR $1.13,95 \%$ CI 1.07-1.19) and electrolyte disorders (PR 1.11, 95\% CI 1.03-1.20) were the more common reasons for hospital admission among patients with diabetes compared with those without.

Stratifying by sex did not significantly change our results, with the exception of electrolyte disorders (PR $1.23,95 \%$ CI $1.09-1.38$ in males but not statistically significant in females) and pneumonia (PR 0.88, 95\% CI 0.82 0.94 in males; PR 0.93 , 95\% CI $0.86-1.00$ in females) (Appendix 3, available at www.cmajopen.ca/content/9/2/ E406/suppl/DC1).

\begin{tabular}{|lccc|}
\hline \multicolumn{4}{|l|}{ Table 1: Characteristics of study participants, stratified by diabetes status } \\
\hline Characteristic & $\begin{array}{c}\text { Overall } \\
n=150499\end{array}$ & $\begin{array}{c}\text { Diabetes } \\
n=41934\end{array}$ & $\begin{array}{c}\text { No diabetes } \\
n=108565\end{array}$ \\
\hline Age, yr, median (IQR) & $73(56-83)$ & $74(63-82)$ & $72(53-84)$ \\
\hline Female sex, no. (\%) & $74935(49.7)$ & $22366(53.3)$ & $52569(48.4)$ \\
\hline No. of comorbidities, median (IQR) & $6(3-8)$ & $7(5-10)$ & $5(3-8)$ \\
\hline Cost of admission in Can\$, mean \pm SD & $10796 \pm 25316$ & $12165 \pm 27278$ & $10268 \pm 24497$ \\
\hline Note: IQR = interquartile range, SD = standard deviation. & & \\
\hline
\end{tabular}

\begin{tabular}{|c|c|c|c|c|c|c|}
\hline \multirow[b]{2}{*}{$\begin{array}{l}\text { Most common reason } \\
\text { for hospital admission }\end{array}$} & \multicolumn{3}{|c|}{ Prevalence, no. $(\%)^{*}$} & \multicolumn{3}{|c|}{$\begin{array}{l}\text { Cost of admission, } \\
\text { median, Can\$ }\end{array}$} \\
\hline & $\begin{array}{c}\text { Overall } \\
n=150499\end{array}$ & $\begin{array}{c}\text { Diabetes } \\
n=41934\end{array}$ & $\begin{array}{l}\text { No diabetes } \\
n=108565\end{array}$ & Overall & Diabetes & No diabetes \\
\hline Heart failure & $7675(5.1)$ & $3228(7.7)$ & $4447(4.1)$ & 6716 & 6821 & 6670 \\
\hline Urinary tract infection & $6902(4.6)$ & $2139(5.1)$ & $4763(4.4)$ & 5071 & 5442 & 4427 \\
\hline Stroke & $6652(4.4)$ & $2020(4.8)$ & $4632(4.3)$ & 7122 & 8270 & 6922 \\
\hline Pneumonia & $7465(5.0)$ & $1929(4.6)$ & $5536(5.1)$ & 6009 & 6183 & 5902 \\
\hline COPD & $6648(4.4)$ & $1861(4.4)$ & $4787(4.4)$ & 6148 & 6278 & 6095 \\
\hline Delirium & $4388(2.9)$ & $1351(3.2)$ & $3037(2.8)$ & 12831 & 12916 & 12700 \\
\hline Acute renal failure & $2760(1.8)$ & $1209(2.9)$ & $1551(1.4)$ & 6238 & 6301 & 6025 \\
\hline Sepsis & $3710(2.5)$ & $1189(2.8)$ & $2521(2.3)$ & 10216 & 10722 & 10025 \\
\hline $\begin{array}{l}\text { Soft tissue and bone } \\
\text { infections }\end{array}$ & $3144(2.1)$ & $1038(2.5)$ & 2106 (1.9) & 6721 & 8794 & 5845 \\
\hline Electrolyte disorders & $3382(2.2)$ & $1016(2.4)$ & 2366 (2.2) & 3768 & 4422 & 3679 \\
\hline
\end{tabular}




\begin{tabular}{|c|c|c|c|}
\hline & & \multicolumn{2}{|c|}{ Cost of admission in diabetes } \\
\hline & & Increased $^{*}$ & Not increased \\
\hline \multirow[t]{2}{*}{$\begin{array}{l}\text { Prevalence } \\
\text { of admission } \\
\text { in diabetes }\end{array}$} & Increased* $^{*}$ & $\begin{array}{l}\text { Stroke } \\
\text { Urinary tract infection } \\
\text { Soft tissue and bone } \\
\text { infections } \\
\text { Electrolyte disorders }\end{array}$ & $\begin{array}{l}\text { Acute renal failure } \\
\text { Heart failure } \\
\text { Sepsis } \\
\text { Delirium }\end{array}$ \\
\hline & Not increased & & $\begin{array}{l}\text { Pneumonia } \\
\text { COPD }\end{array}$ \\
\hline
\end{tabular}

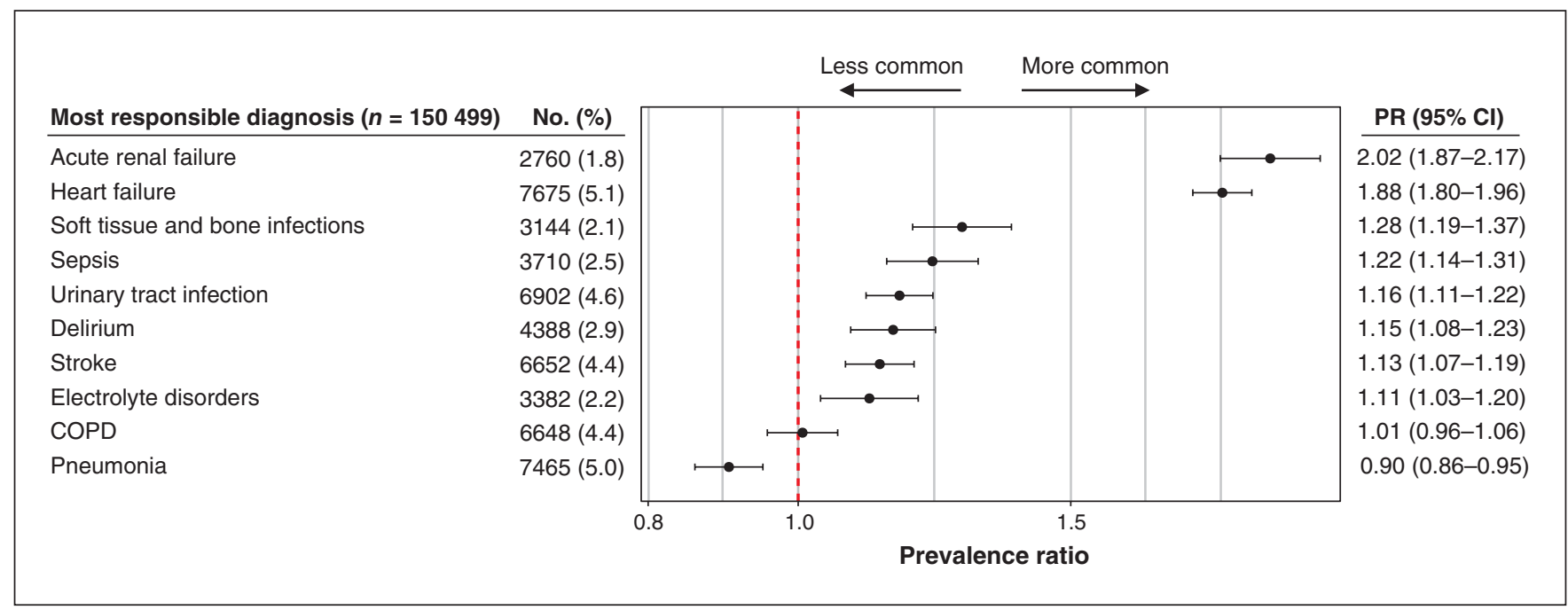

Figure 1: Prevalence ratios with error bars of most responsible reasons for diagnosis. Note: $\mathrm{Cl}=$ confidence interval, COPD $=$ chronic obstructive pulmonary disease, $\mathrm{PR}=$ prevalence ratio.

\section{Cost of admissions}

The median costs of admission (Table 2) for each of the most common reasons for admission among patients with diabetes were $\$ 12916$ for delirium, $\$ 10722$ for sepsis, $\$ 8794$ for soft tissue and bone infections, $\$ 8270$ for stroke, $\$ 6821$ for heart failure, $\$ 6301$ for acute renal failure, $\$ 6278$ for chronic obstructive pulmonary disease, $\$ 6183$ for pneumonia, $\$ 5442$ for urinary tract infection and $\$ 4422$ for electrolyte disorders.

The CRs for these conditions (Figure 2, Table 3) showed that admission for soft tissue and bone infections (CR 1.50, 95\% CI 1.37-1.65), urinary tract infection (CR 1.23, 95\% CI 1.17-1.29), electrolyte disorders (CR 1.20, 95\% CI 1.08-1.34) and stroke (CR 1.19, 95\% CI 1.14-1.25) were more costly among patients with diabetes compared with those without. The proportional difference in cost of admission for heart failure, pneumonia and chronic obstructive pulmonary disease were statistically significant but were not greater than our threshold of $10 \%$.

Stratifying by sex did not significantly change our results, with the exception of acute renal failure (CR 1.13, 95\% CI
1.01-1.26 in females; not statistically significant in males), urinary tract infection (CR 1.23, 95\% CI 1.19-1.28 in females; not statistically significant in males) and sepsis (CR $1.25,95 \%$ CI $1.15-1.35$ in males; not statistically significant in females) (Appendix 3).

\section{Sensitivity analyses}

Sensitivity analyses that used only the first hospital admission for each patient $(n=96073)$ did not significantly change our results. Adjustment for age is included in the CIHI RIW methodology used for cost estimation, and adjustment for inflation did not significantly change our results ${ }^{14}$ (Appendices 4 and 5, available at www.cmajopen.ca/content/9/2/E406/ suppl/DC1).

\section{Interpretation}

In our study of patients admitted to the general internal medicine services at 7 Toronto hospitals, nearly one-third had diabetes. Soft tissue and bone infections, urinary tract infections, stroke and electrolyte disorders were more frequent and costly 


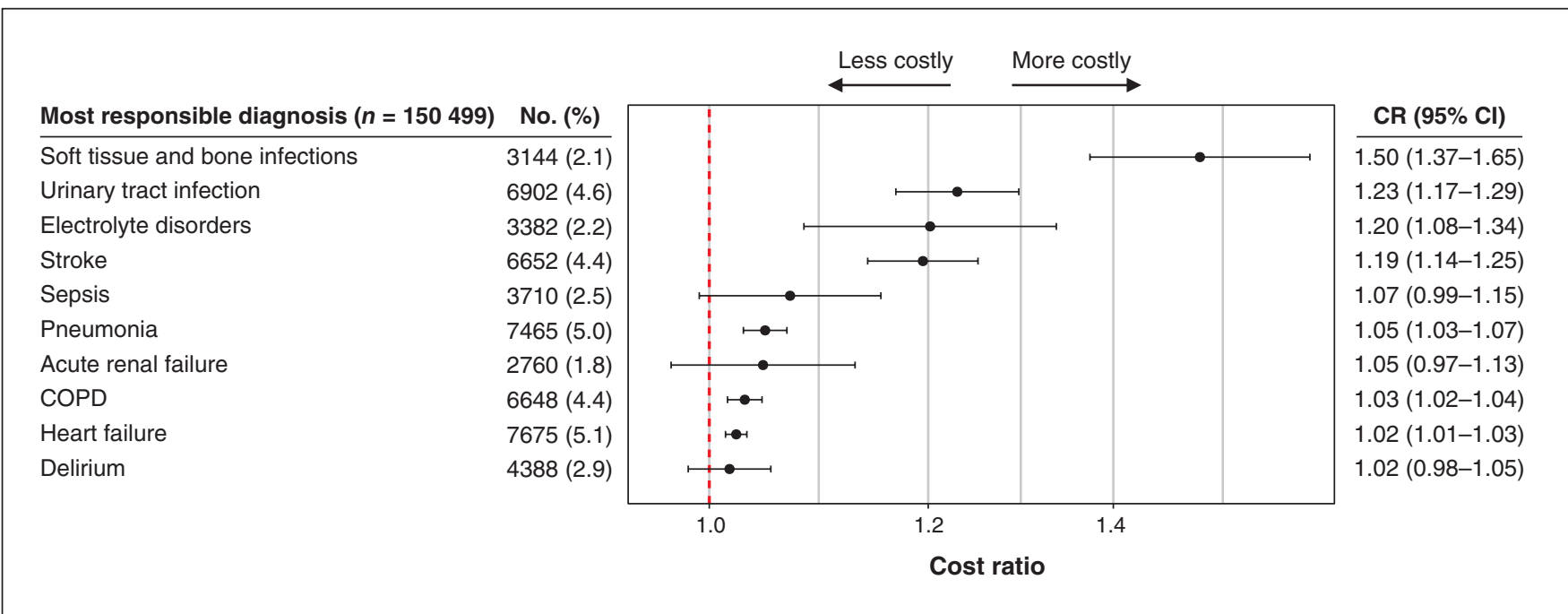

Figure 2: Cost ratios with error bars of most responsible reasons for diagnosis. Note: $\mathrm{Cl}=$ confidence interval, $\mathrm{COPD}=$ chronic obstructive pulmonary disease, $\mathrm{CR}=$ cost ratio.

among patients with diabetes than among patients without. In addition, hospital admissions for acute renal failure, heart failure, sepsis and delirium occurred at a greater frequency in the diabetes population, but not at an increased cost.

Diabetes is a highly prevalent and potential driver of illness among patients admitted to hospital. A recent study found hypertension to be the most common comorbid condition among patients admitted to hospital with diabetes as the primary reason for admission. ${ }^{23}$ However, as we have shown, diabetes itself is rarely a reason for admission; rather, its associated morbidities frequently lead to hospital admissions owing to complications including soft tissue and bone infections, urinary tract infections, stroke and electrolyte disorders. This study provides essential information for clinicians and policy makers to understand the broader impact of diabetes on hospital admissions.

Our findings on stroke add to existing knowledge: patients with diabetes have about twice the risk of stroke as those without diabetes. ${ }^{24}$ Rates of stroke have fallen substantially over the last few decades in response to the growing evidence in support of cardioprotective therapies and their adoption in clinical practice. ${ }^{25}$ Yet, based on our evidence, admissions for stroke remain more common in patients with diabetes.

Compared with stroke prevention, the prevention of soft tissue and bone infections has received less attention in the research literature, potentially at the expense of increased morbidity and mortality. ${ }^{26}$ In Canada and the US, decades of improvements in rates of nontraumatic lower-extremity amputations in patients with diabetes have recently reversed, especially among younger adults. ${ }^{27-29}$ A 2017 international meta-analysis comparing the prevalence of diabetic foot ulcers across 33 countries has found Canada (14.8\%) to have the second highest rate, after Belgium (16.6\%). ${ }^{30}$ Foot care is one of the most neglected components of standard diabetes care practices, with only $51 \%$ of Canadian patients with diabetes having their feet checked as recommended. ${ }^{31}$ With the exception of recent coverage in Ontario, offloading devices are not currently covered for Canadians with diabetes who have foot ulcers. ${ }^{32}$ In addition, the prevalence of diabetes is higher in lower-income households, ${ }^{33}$ providing real-life context to the $57 \%$ of Canadians with diabetes who cannot afford their necessary medications, devices and supplies. ${ }^{34}$

To curb such trends in soft tissue and bone infections, proven preventive measures, including regular foot examination, debridement, mechanical offloading devices and chiropody, must not only be available, but also easily accessible for patients with diabetes who often lack economic or social capital. As part of increasing efforts to integrate information technology into medicine,,$^{35}$ the use of telemedicine ${ }^{36}$ and social media $^{37}$ in diabetes foot care may help fill in gaps in accessibility and knowledge dissemination. Given the projected increase in the burden of diabetic foot ulcers, including frequent and costly admissions to hospital as shown in our study, increased primary care efforts and public funding should be directed specifically toward proven preventive strategies and modernized approaches. ${ }^{38}$

Most of the diabetes-related conditions identified in our study were vascular in nature, except for urinary tract infections, delirium and electrolyte disorders. The increased burden of hospital admission secondary to urinary tract infections in patients with diabetes is consistent with existing knowledge. ${ }^{39}$ Diabetes is associated with a higher risk of asymptomatic bacteriuria, urinary tract infections and severe complications. Whether patients with diabetes should be treated if they have asymptomatic bacteriuria is unknown and may be an important focus of future research. In addition, ongoing review of the safety of sodium-glucose cotransporter-2 inhibitors, which are gaining prominence in diabetes care, is needed to understand its impact on urinary tract infections among patients with diabetes. ${ }^{40}$

Although delirium may be caused by any of the identified comorbid conditions, there is limited literature on how diabetes itself can predispose an individual to delirium. Diabetes has been associated with both Alzheimer disease and vascular 
dementia, ${ }^{41}$ yet studies on its association with delirium have yielded mixed results and have been conducted primarily in an intensive care setting. ${ }^{42}$ One plausible hypothesis is that the generation of microvascular malformations in the central nervous system from persistent metabolic derangements leads to endothelial damage and deregulated angiogenesis. ${ }^{43}$ Given that the prevalence of delirium among our patients with diabetes was $15 \%$ greater than among those without, further studies are warranted to understand the mechanism behind this increased prevalence.

Electrolyte disorders were one of the most frequent and costly reasons for admission in patients with diabetes, yet preventive strategies are lacking. The multifactorial nature of its pathophysiology in diabetes, likely including poor nutrition, impaired gastrointestinal absorption, acid-base abnormalities and pharmacological agents, makes electrolyte abnormalities a challenging condition to prevent. ${ }^{44}$ Further studies that aim to elucidate the individual pathophysiologic mechanisms of electrolyte disorders in patients with diabetes will be necessary to develop outpatient strategies for monitoring and prevention.

Finally, heart failure was the most common reason for hospital admission among patients with diabetes, a relation that has been well established. ${ }^{45}$ New treatment options for this particular demographic have been emerging. For instance, a meta-analysis evaluating cardiovascular outcomes among patients with type 2 diabetes using sodiumglucose cotransporter-2 inhibitors found that these medications have shown promising effects of reducing hospital admissions secondary to heart failure by about $30 \%$, regardless of presence of atherosclerotic cardiovascular disease or heart failure at baseline. ${ }^{46}$

\section{Limitations}

There are several limitations to our study. Our patients with diabetes were restricted to those who were admitted to a general internal medicine service for some portion of their hospital admission and did not include patients admitted to surgical, psychiatric or subspecialty medical services. Thus, the frequency of admissions secondary to diabetes-related complications or severe complications may be underestimated. However, more than one-third of emergency department admissions are to a general internal medicine service; therefore, our data capture the largest group of patients requiring hospital admission and represent a crucial health services group on which to focus. ${ }^{11}$

Our cost estimates did not take physician billing and outpatient expenses into account; therefore, the costs of admission may have been underestimated, which may have affected the CR methods we adopted. Using the RIW, we were able to estimate the cost of hospital admission, but not out-of-pocket costs such as mechanical offloading devices. However, RIW has been used previously in similar studies ${ }^{7,47}$ and provides a reasonable and comparable estimation of the direct health care costs attributable to diabetes.

There remains a residual risk of clustering at the hospital, physician and admission levels. We conducted sensitivity analyses using only the first hospital admission, and the results were robust. Our patient population came from only 2 cities in Canada. However, our inclusion of the 5 largest hospitals in Toronto and the only 2 hospitals in Mississauga, Canada's first and ninth most populous municipalities respectively, adds to the generalizability of our findings. Lastly, the number of comorbid conditions in the comparison of patients with diabetes and patients without diabetes was not adjusted.

\section{Conclusion}

A substantial portion of acute hospital admissions are associated with diabetes. Our study characterizes the frequency and costs associated with acute inpatient hospital admissions to a general internal medicine service from various diabetesrelated conditions. Based on our findings, a preventive strategy focused on reducing hospital admissions secondary to soft tissue and bone infections, urinary tract infections, stroke and electrolyte disorders in patients with diabetes may be beneficial in this high-risk group.

\section{References}

1. Guariguata L, Whiting DR, Hambleton I, et al. Global estimates of diabetes prevalence for 2013 and projections for 2035. Diabetes Res Clin Pract 2014;103:137-49.

2. Diabetes in Canada: backgrounder. Toronto: Diabetes Canada; 2020. Available: https://www.diabetes.ca/DiabetesCanadaWebsite/media/Advocacy-and-Policy/ Backgrounder/2020_Backgrounder_Canada_English_FINAL.pdf (accessed 2017 Dec. 15).

3. American Diabetes Association. Economic costs of diabetes in the U.S. in 2017. Diabetes Care 2018;41:917-28.

4. Boyle JP, Thompson TJ, Gregg EW, et al. Projection of the year 2050 burden of diabetes in the US adult population: dynamic modeling of incidence, mortality, and prediabetes prevalence. Popul Health Metr 2010;8:29.

5. Economic burden of illness in Canada, 2005-2008: protecting Canadians from illness. Ottawa: Public Health Agency of Canada; 2014.

6. Bilandzic A, Rosella L. The cost of diabetes in Canada over 10 years: applying attributable health care costs to a diabetes incidence prediction model. Health Promot Chronic Dis Prev Can 2017;37:49-53.

7. Rosella LC, Lebenbaum M, Fitzpatrick T, et al. Impact of diabetes on healthcare costs in a population-based cohort: a cost analysis. Diabet Med 2016;33:395-403.

8. Cavender MA, Steg PhG, Smith SC Jr, et al.; REACH Registry Investigators. Impact of diabetes mellitus on hospitalization for heart failure, cardiovascular events, and death: outcomes at 4 years from the Reduction of Atherothrombosis for Continued Health (REACH) registry. Circulation 2015;132:923-31.

9. Megherbi S-E, Milan C, Minier D, et al.; European BIOMED Study of Stroke Care Group. Association between diabetes and stroke subtype on survival and functional outcome 3 months after stroke: data from the European BIOMED Stroke Project. Stroke 2003;34:688-94.

10. Thakar CV, Christianson A, Himmelfarb J, et al. Acute kidney injury episodes and chronic kidney disease risk in diabetes mellitus. Clin 7 Am Soc Nephrol 2011;6:2567-72.

11. Verma AA, Guo Y, Kwan JL, et al. Patient characteristics, resource use and outcomes associated with general internal medicine hospital care: the General Medicine Inpatient Initiative (GEMINI) retrospective cohort study. CMA7 Open 2017;5:E842-9.

12. Pasricha SV, Jung HY, Kushnir V, et al. Assessing the quality of clinical and administrative data extracted from hospitals: the General Medicine Inpatient Initiative (GEMINI) experience. medRxiv 2020 Mar. 18. doi: 10.1101/2020.03.16.20036962.

13. DAD resource intensity weights and expected length of stay (ELOS) for $C M G+2015$. Ottawa: Canadian Institute for Health Information; 2015.

14. Wodchis WP, Bushmeneva K, Nikitovic M, et al. Guidelines on person-level costing using administrative databases in Ontario. Working Paper Series, Vol. 1. Toronto: Health System Performance Research Network; 2013.

15. Concept: Case Mix Groups $\left(\mathrm{CMG}^{\mathrm{TM}}\right)$ : overview. Winnipeg: Manitoba Centre for Health Policy, University of Manitoba; updated 2010 Nov. 4. Available: http://mchp-appserv.cpe.umanitoba.ca/viewConcept.php? conceptID=1094 (accessed 2020 Mar. 16).

16. Jolley RJ, Quan H, Jetté N, et al. Validation and optimisation of an ICD-10coded case definition for sepsis using administrative health data. BMF Open 2015;5:e009487.

17. Tu K, Mitiku T, Guo H, et al. Myocardial infarction and the validation of physician billing and hospitalization data using electronic medical records. Chronic Dis Can 2010;30:141-6. 
18. Gomes T, Martins D, Tadrous M, et al. Association of a blood glucose test strip quantity-limit policy with patient outcomes: a population-based study. 7AMA Intern Med 2017;177:61-6.

19. Filion KB, Azoulay L, Platt RW, et al.; CNODES Investigators. A multicenter observational study of incretin-based drugs and heart failure. $N$ Engl 7 Med 2016;374:1145-54.

20. Price RM, Bonett DG. Distribution-free confidence intervals for difference and ratio of medians. 7 Stat Comput Simul 2002;72:119-24. doi: 10.1080/00949650212140.

21. Rothman KJ. Epidemiology: an introduction. Oxford (UK): Oxford University Press; 2012.

22. Guidance document for the costing of health care resources in the Canadian setting. 2nd ed. Ottawa: Canadian Agency for Drugs and Technologies in Health; 2015.

23. Wielgosz A, Dai S, Walsh P, et al. Comorbid conditions in Canadians hospitalized because of diabetes. Can 7 Diabetes 2018;42:106-11.

24. Emerging Risk Factors Collaboration; Sarwar N, Gao P, Kondapally Seshasai $\mathrm{SR}$, et al. Diabetes mellitus, fasting blood glucose concentration, and risk of vascular disease: a collaborative meta-analysis of 102 prospective studies. Lancet 2010;375:2215-22.

25. Fang MC, Perraillon MC, Ghosh $\mathrm{K}$, et al. Trends in stroke rates, risk, and outcomes in the United States, 1988 to 2008. Am 7 Med 2014;127:608-15.

26. Gregg EW, Sattar N, Ali MK. The changing face of diabetes complications. Lancet Diabetes Endocrinol 2016;4:537-47.

27. Geiss LS, Li Y, Hora I, et al. Resurgence of diabetes-related nontraumatic lower-extremity amputation in the young and middle-aged adult US population. Diabetes Care 2019;42:50-4.

28. Hussain MA, Al-Omran M, Salata K, et al. Population-based secular trends in lower-extremity amputation for diabetes and peripheral artery disease. CMAJ 2019;191:E955-61.

29. Syed MH, Salata K, Hussain MA, et al. The economic burden of inpatient diabetic foot ulcers in Toronto, Canada. Vascular 2020;28:520-9.

30. Zhang $\mathrm{P}$, Lu J, Jing Y, et al. Global epidemiology of diabetic foot ulceration: a systematic review and meta-analysis. Ann Med 2017;49:106-16.

31. Diabetes care gaps and disparities in Canada. Ottawa: Canadian Institute for Health Information; 2009.

32. Registered Nurses' Association of Ontario. Health professionals applaud Ontario's decision to fund devices for people with diabetic foot ulcers [press release]. Cision 2017 Nov. 22.

33. Chronic Disease and Injury Indicator Framework: Quick Facts, Fall 2014 Edition. Vol 34, No 4. Ottawa: Centre for Chronic Disease Prevention, Public Health Agency of Canada; 2014.

34. The burden of out-of-pocket costs for Canadians with diabetes. Toronto: Diabetes Canada; 2011.

35. Blumenthal D. Stimulating the adoption of health information technology. $N$ Engl 7 Med 2009;360:1477-9.

36. Kolltveit B-CH, Gjengedal E, Graue M, et al. Conditions for success in introducing telemedicine in diabetes foot care: a qualitative inquiry. $B M C$ Nurs 2017;16:2.

37. Abedin T, Al Mamun M, Lasker MAA, et al. Social media as a platform for information about diabetes foot care: a study of Facebook groups. Can 7 Diabetes 2017;41:97-101.

38. Impact of offloading devices on the cost of diabetic foot ulcers in Ontario. Toronto: Diabetes Canada; 2016.

39. Stapleton A. Urinary tract infections in patients with diabetes. Am $7 \mathrm{Med}$ 2002;113(Suppl 1A):80S-4S.

40. Liu J, Li L, Li S, et al. Effects of SGLT2 inhibitors on UTIs and genital infections in type 2 diabetes mellitus: a systematic review and meta-analysis. Sci Rep 2017;7:2824.

41. Biessels GJ, Staekenborg S, Brunner E, et al. Risk of dementia in diabetes mellitus: a systematic review. Lancet Neurol 2006;5:64-74.
42. van Keulen K, Knol W, Belitser SV, et al. Diabetes and glucose dysregulation and transition to delirium in ICU patients. Crit Care Med 2018;46:1444-9.

43. Breier G, Chavakis T, Hirsch E. Angiogenesis in metabolic-vascular disease. Thromb Haemost 2017;117:1289-95.

44. Liamis G, Liberopoulos E, Barkas F, et al. Diabetes mellitus and electrolyte disorders. World $\mathcal{F}$ Clin Cases 2014;2:488-96.

45. Nichols GA, Hillier TA, Erbey JR, et al. Congestive heart failure in type 2 diabetes: prevalence, incidence, and risk factors. Diabetes Care 2001;24:1614-9.

46. Zelniker TA, Wiviott SD, Raz I, et al. SGLT2 inhibitors for primary and secondary prevention of cardiovascular and renal outcomes in type 2 diabetes: a systematic review and meta-analysis of cardiovascular outcome trials. Lancet 2019;393:31-9.

47. Simpson SH, Corabian P, Jacobs P, et al. The cost of major comorbidity in people with diabetes mellitus. CMA7 2003;168:1661-7.

Affiliations: Department of Medicine (Choi), University of Toronto; Li Ka Shing Knowledge Institute (Booth, Jung, Verma, Razak) and Department of Medicine, Division of Endocrinology (Booth), St. Michael's Hospital; Division of General Internal Medicine (Lapointe-Shaw, Rawal), University Health Network; Program of Medicine and Institute for Better Health (Tang), Trillium Health Partners; Division of General Internal Medicine (Kwan), Mount Sinai Hospital; Division of General Internal Medicine (Weinerman), Sunnybrook Health Sciences Centre; Division of General Internal Medicine (Verma, Razak), St. Michael's Hospital, Toronto, Ont.

Contributors: Jin Choi wrote the first draft of the manuscript. Hae Jung provided statistical analysis. Jin Choi, Gillian Booth, Amol Verma and Fahad Razak contributed to the interpretation of data, critically revised the manuscript. Lauren Lapointe-Shaw, Terence Tang, Janice Kwan, Shail Rawal and Adina Weinerman critically revised the manuscript. Amol Verma and Fahad Razak are joint senior authors. All authors gave final approval of the version to be published and agreed to be accountable for all aspects of the work.

Funding: The General Internal Medicine Inpatient Initiative (GEMINI) study was supported by grants from Green Shield Canada Foundation and the Division of General Internal Medicine, University of Toronto. Fahad Razak is supported by an award from the Mak Pak Chiu and Mak-Soo Lai Hing Chair in General Internal Medicine, University of Toronto.

Content licence: This is an Open Access article distributed in accordance with the terms of the Creative Commons Attribution (CCBYNCND 4.0) licence, which permits use, distribution and reproduction in any medium, provided that the original publication is properly cited, the use is noncommercial (i.e., research or educational use), and no modifications or adaptations are made. See: https://creativecommons.org/ licenses/by-nc-nd/4.0/

Data sharing: The data from this study are held securely by GEMINI at Unity Health Toronto. Under the data-sharing agreement involving the affiliated hospitals, the data are not accessible to others. Analysis using these data must be performed by a GEMINI analyst or approved user within the secure data environment provided by Unity Health.

Supplemental information: For reviewer comments and the original submission of this manuscript, please see www.cmajopen.ca/content/9/2/ E406/suppl/DC1. 